\title{
Strategic Planning And Performance Of Businesses In Ghana: A Comparative Study Of Micro, Small, And Large Firms
}

Ahmed Agyapong, Kwame Nkrumah University of Science and Technology, Ghana Abdul Samed Muntaka, Kwame Nkrumah University of Science and Technology, Ghana

\begin{abstract}
Over the last three decades, numerous studies have been conducted on the relationship between strategic planning and organizational performance; all these studies have yielded inconclusive results. This article investigates this relationship using data from micro, small, and large firms operating in a developing economy. The results suggest that the planning-performance relationship is positive and very significant in micro level firms where strategic planning approximates disequilibrium. In small firms, we found that this relationship was positive and moderately significant. In large firms where strategic planning approximates equilibrium, however, the planning-performance relationship was positive but not significant. Accordingly, we present a new dimension to the strategic-planning-performance debate and suggest that the relationship differs on the basis of the firm's level/size and economic environment.
\end{abstract}

Keywords: Businesses; Micro; Planning; Performance; Large; Firms; Small; Strategic

\section{INTRODUCTION}

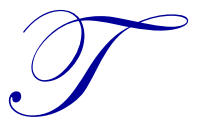

he link between strategic planning and business performance has posed a profound dilemma for strategic management researchers. Empirical studies have produced many contradictory findings and have been criticized for their weak theoretical underpinning and negligible practical importance (Pearce, 1987; Powell, 1992). Although many studies have attempted to resolve this impasse (Pearce, 1987; Armstrong, 1991; Rue and Ibrahim, 1998; Perry, 2001; Yusuf and Saffu, 2005), no consensus concerning methodological approaches or findings has been reached. It is worryingly clear that pushing for any empirical reconciliation will not fly in the face of the evidence. Fortunately, Powell (1992) provides a vibrant logic for fixing this empirical conundrum. Drawing from a resource perspective, the author suggests the possibility of reconciling the contradictions in previous studies and achieving consistent and meaningful empirical results in planningperformance research. Powell (1992) argues that, in settings where strategic planning has become widely disseminated or where a condition approximating planning equilibrium exists, the correlation between strategic planning and performance does not differ significantly from zero; however, the opposite is true for settings with imperfect planning dissemination (i.e., with planning disequilibrium).Hence, as planning dissemination increases, the impact of strategic planning on business performance diminishes. This paper follows the line of inquiry suggested by Powell (1992) and makes a crucial contribution to the growing literature.

This paper also contributes to the literature by focusing on the African context, particularly Ghana. The only recent study that has focused on Ghana is Yusuf and Saffu (2005). We deviate from Powell's (1992) focus on industrial analysis by focusing only on micro, small, and large business organizations in Ghana. We however follow Powell (1992), while placing it within the Ghanaian context, by suggesting that the planning dissemination of micro and small firms is poor because most informal sector businesses do not commit themselves to any well-structured or defined strategic planning. Therefore, we expect a positive and significant linkage between planning orientation and business performance for micro and small firms and, by implication, for the informal sector. However, because large firms in Ghana undertake vigorous planning exercises, their planning is expected to correlate positively but less significantly with performance. 
The findings indicate that planning activities increase as a firm increases in scale. Thus, micro firms seldom undertake strategic planning, whereas large firms undertake intense planning. Furthermore, it was observed that the correlation between overall planning and performance was greater for micro firms than for small and large firms, confirming the view that the impact of planning on performance diminishes as a firm approaches a planning equilibrium state.

\section{STRATEGIC PLANNING AND PERFORMANCE}

Strategy is multifaceted and very difficult to define from a single perspective. It has as many definitions and models as studies devoted to it. In these studies, researchers have identified the factors that influence strategy. Channon (1973) examined the influence of organizational structure. Porter (1980) argued that industrial analyses bring out the true extent of the meaning and scope of strategy. Mintzberg (1987) indicated that strategy is not a predetermined phenomenon but one that has to emerge. Stacey (1993) considered strategy from the cultural perspective, and Leavy and Wilson (1994) focused on leadership. These studies enlarged the scope of strategy research but have not provided a conclusive definition of strategy. It is generally agreed, however, that strategy is related to configuring the resources available within or to an organization in order to achieve its goals. This study defines strategy as the systematic and continuous approach to aligning organizational capacity with the organization's mission and vision for maximizing the use of the organization's resources and achieving competitive advantage.

Strategic planning is more diversified than strategy. This study agrees with Mathew and Michael (2009), who stated that the broad explanation of "strategic planning" as an umbrella term including activities such as planning, performance measurement, program budgeting, etc. This notion is very useful but limited. This is because strategic planning also covers other factors such as the business environment and level of competition. The relationship between strategic planning and performance in general and financial performance in particular has been inconclusive. Powell (1992) indicates, for example, that the extensive planning-performance studies were confusing, contradictory, and impossible to reconcile. He further indicates that positive planning-performance relationships outnumbered negative ones" and that "out of fifteen studies reviewed, Armstrong (1986) counted ten positive planning-performance relationships, two negative relationships, and three non-significant relationships. Meanwhile Shrader et al. (1984) counted 20 positive relationships, 11 non-significant relationships and no negative relationship." The desire to arrive at a definitive conclusion led to further reviews with claims and counter claims. It must be noted however, that performance measures are essential for managing and navigating organizations through turbulent and competitive global markets. They enable organizations to track the progress of their strategy, identify areas requiring improvement, and use them as benchmarks against competitors or industry leaders. The information provided by performance measures enables managers to make the right decisions at the right time (Gunasekaran et al., 2004).

The question is, then, whether strategic planning really influences performance. Although it is difficult to draw an answer from the current literature, it is worth indicating that the numerous reviews conducted over the years have generated more statistically significant positive results than negative ones (Powell, 1992). Kaplan and Norton (1992) argue, however, that traditional performance measures have been oriented to financial metrics such as returns on capital employed and profit, which record how organizations have performed but not necessarily how they will perform in the future. Although traditional financial performance measures worked well in the past, they are outdated and do not support the skills and competencies that organizations currently need to master.

Powell (1992) argues that we need not condemn previous planning-performance studies for incompetence or duplicity because they have produced precisely the expected result if strategic planning is indeed an economically valuable, but imitable and substitutable, strategic factor. He concludes by adding that the studies may have used imperfect methodologies but indicates that they did not produce the apparent contradictions, which, he believes, resulted from our own assumption that the planning-performance relationship remains constant over time, a notion that lacks theoretical grounding. Our empirical study examines the planning-performance relationship across six industries with significantly different levels of planning dissemination. 
It must be noted that most planning-performance studies have been conducted in advanced industrialized countries. Little is known about strategic planning levels in Africa. Hunger (1990) indicated that strategic planning approximates equilibrium in developed countries because strategic planning tools and techniques have been widely disseminated there over the past 25 years, and strategic planning may therefore not have a highly statistically significant relationship with performance. In explaining the level of strategic planning in advanced industrialized countries, Abrahamson and Bartner (1990) add such factors as increased enrolments in business degree programs and executive seminars, the inter-firm migration of executives and planning staff, low entry barriers to the strategic planning consulting industry, and proliferation of strategic planning books, articles, and bandwagon effects. From the above insights, it can be reasonably argued that in less developed countries like Ghana, strategic planning will approximate disequilibrium, because the use of strategic planning tools and techniques are not popular in those countries. Therefore, strategic planning could have a very significant relationship with performance. In addition, in less developed countries like Ghana, strategic planning does not approximate uniform disequilibrium because large firms are more likely to conduct strategic planning than micro and small firms. Most of Ghana's micro and small firms operate in the informal sector (Acquaah, 2011), where planning is ad hoc or non-existent. Accordingly, we propose the following hypotheses:

Hypothesis 1: The relationship between strategic planning and performance in large firms will not differ significantly from zero.

Hypothesis 2: The relationship between strategic planning and performance will be greater in micro and small firms than in large firms.

Hypothesis 3: The correlation between strategic planning and performance is significantly greater in micro and small firms than in large firms.

\section{METHODOLOGY AND MEASUREMENTS}

Our focus is on micro, small, and large firms in a developing country, Ghana. A micro firm is one with 10 employees or fewer. A small firm has between 10and 99 employees, and a large firm has more than 99 employees. A sample of 600 firms, 200 firms for each level, was chosen for the study and each of these firms were sent questionnaires. Overall, 201 questionnaires were returned, giving a response rate of $33.5 \%$, which is considered acceptable in light of the high proportion of private and informal firms and the direct involvement of their CEOs. However, the response rate varied among the levels and of the 201 responses, 88 were received from micro firms, 64 from small firms, and 38 from large firms. Since a number of demographic variables can affect firm performance, we collected information on the age, firm tenure (Hambrick and Mason, 1984), and management positions of the respondents (Hambrick, 1981b; Ireland et al., 1987). The reliability level of the questionnaire was found to be 0.725 using Cronbach's Alpha.

Performance was operationalized as a Return on Assets (ROA). Managers were asked to indicate their firm's performance over three years, a common practice. Following Daft et al., (1988), ROA (the dependent variable) was averaged over three years (from 2009 to 2011) to reduce data aberration. Even though objective measures would have been most appropriate, subjective performance measures have been widely used in strategyrelated research (Robinson and Pearce, 1988). Given that our sample was composed mostly of micro and small businesses, it was assumed that extracting adequate and reliable financial information would be difficult. Moreover, anonymity precluded the collection of such data from secondary sources. The financial data on micro and small businesses have also been criticized for being unreliable and subject to varying accounting conventions or even to managerial manipulation (from those attempting to avoid corporate or personal taxes, for example; see Powell and Dent-Micallef, 1997). The independent variable, strategic planning, was measured using goal setting, environmental scanning, and analysis based on the scales used by Powell (1992). Respondents were asked to indicate on a scale from 0 to 5 , the accuracy of 11 statements about their firm's strategy making. The scale was anchored at either extreme with the responses "Very accurate" and "Not at all accurate." 


\section{DATA ANALYSIS AND RESULTS}

The standard deviations and means for all the variables were calculated together with zero-order correlations as shown in Table 1. The results indicate that the intensity of the planning activities decreases as the means of the large firms' strategic planning variants (analysis, scanning, and goals setting) become higher than those of the micro and small firms. This confirms the proposition that the tools, models, and techniques used in strategic planning are more popular among the large firms than among the small and micro firms; hence, planning dissemination is stronger and more vibrant in large firms than in small and micro firms. An ANOVA test confirmed that, in general, the mean difference for overall planning is significant at $p<0.05$ using a two-tailed t-test. At the firm classification level, the mean difference in overall planning between large and small firms and between large and micro scale firms is significantly different from zero, based on Scheffe's multiple range test at $p<0.05$.For small and micro firms, however, we observed an insignificant difference in overall planning mean ratios. These results indicate that informal sector planning is relatively uncommon, but companies begin to open up to strategies and formal structures in pursuit of enhanced performance as they grow. Hence, the informal sector of the Ghanaian economy reflects a planning disequilibrium.

The relationship between planning and profits confirms the deduction in hypothesis 1 that strategic planning is positively related to performance, but this relationship is insignificant for large firms and positively significant for micro and small firms. Furthermore, the relationship between strategic planning and performance is stronger for micro and small firms than for large firms, corroborating with hypothesis 2 . This result also confirms Powell's (1992) assumption that the link between strategic planning and performance does not remain constant over time, because the empirical association erodes as the business environment approximates a planning equilibrium.

The next level of inquiry is whether the impact of strategic planning on performance is propelled by intrinsic characteristics associated with the decision makers or whether planning is a part of corporate culture. This effect was captured using the CEO locus of control as the variable of interest, which was employed because CEOs with internalized loci of control may provide optimistic performance estimates while attributing them to their strategic planning and foresight (Miller et al., 1982, cited in Powell, 1992). Lewin and Stephens (1994), cited in Boone et al. (1996), also stated that CEOs with internal loci of control feel capable of controlling outcomes and are thus likely to believe in the concept of strategy, engage in strategic planning, implement the structures and processes of environmental monitoring that strategic planning requires, and restructure their organizations to fit the contingencies of their chosen strategies. The results in Table 1 indicate that the companies whose CEOs were surveyed have internal controls that positively relate to both overall planning and performance; however, except for in small firms, this relationship is insignificant. This indicates that, within small firms, planning is more subject to top managers' will to attain success, because of the following reasons. First, the sheer size of large firms may make it difficult for one person to control all the events; therefore, the performance impact on large firms of one overseer may be weaker than the impact on a small firm. For micro firms, the challenges posed by the environment can limit a CEO's drive, which can affect the momentum of success. Second, as planning is ad hoc and rare in the informal sector, the CEOs of expanding businesses are motivated to find the most practical means of increasing performance through strategized learning, because their flexible business structure enables them to affect business outcomes. This may explain why the CEO locus of small firms is greater that in micro firms and is positively significant to overall planning and profits. However, in large firms, CEO control may be limited by the management structure, and the corporate goals may override the internal loci of the top managers. Lefcourt (1982), cited in Boone et al. (1996), concludes, "as such, locus of control can be viewed as a mediator of involved commitment in life pursuits. If one feels helpless to affect important events, then resignation or at least benign indifference should become evident, with fewer signs of concern, involvement, and vitality."

To investigate how these exogenous effects impact the bivariate association between strategic planning and profits, a test of hypothesis 3 was conducted. Hypothesis 3 states that in large firms with a relative planning equilibrium, the partial correlation between strategic planning and profit does not differ significantly from zero, whereas in micro and small firms, a positive and significant correlation is expected. Furthermore, the correlation ratios decrease as they pass from the micro level through to the small and large levels, supporting the proposition that as a setting approximates a planning equilibrium, the impact of strategic planning on performance deteriorates. This observation is presented in Table 2, which shows the partial correlation between strategic planning orientation 
and profits while controlling for the effects of firm size, age, and the CEO's locus of control. This does not imply, however, that large Ghanaian businesses should reduce their current strategic planning levels, despite the nonsignificant planning-performance correlation. The correlation merely reflects the planning equilibrium among the businesses (Powell, 1992).

Table 1: Descriptive Statistics and Correlation of Strategic Planning Orientation by Category of Firm

\begin{tabular}{|c|c|c|c|c|c|c|c|c|c|c|}
\hline \multicolumn{11}{|l|}{ Large Scale Firms } \\
\hline Variables & Mean & S.D. & 1 & 2 & 3 & 4 & 5 & 6 & 7 & 8 \\
\hline 1. Goals & 4.3263 & 0.77064 & 1 & & & & & & & \\
\hline 2. Analysis & 3.7675 & 0.7726 & $.457 * *$ & 1 & & & & & & \\
\hline 3. Scanning & 3.9123 & 0.79671 & 0.149 & $.456^{* *}$ & 1 & & & & & \\
\hline 4. Control & 3.6447 & 0.65148 & 0.134 & 0.299 & 0.108 & 1 & & & & \\
\hline 5. Overall Planning & 3.902 & 0.61991 & $.788 * *$ & $.800^{* *}$ & $.796 * *$ & 0.226 & 1 & & & \\
\hline 6. Size & 2.4762 & 2.4762 & 0.19 & 0.214 & 0.142 & 0.064 & 0.229 & 1 & & \\
\hline 7. Age & 20.7105 & 2.06 & 0.164 & $.332 *$ & -0.530 & 0.104 & 0.183 & 0.084 & 1 & \\
\hline 8. Profit & 20.1592 & 4.71809 & $.429 * *$ & 0.128 & 0.27 & 0.053 & 0.164 & -0.114 & -0.268 & 1 \\
\hline \multicolumn{11}{|l|}{ Small Scale } \\
\hline Variables & Mean & S.D. & 1 & 2 & 3 & 4 & 5 & 6 & 7 & 8 \\
\hline 1. Goals & 3.9141 & 1.08947 & 1 & & & & & & & \\
\hline 2. Analysis & 3.4866 & 0.94633 & $.430 * *$ & 1 & & & & & & \\
\hline 3. Scanning & 3.4973 & 1.18887 & $.348 * *$ & $.532 * *$ & 1 & & & & & \\
\hline 4. Control & 3.5025 & 0.65092 & $.344 * *$ & 0.199 & $.266 *$ & 1 & & & & \\
\hline 5. Overall Planning & 3.5158 & 0.86118 & $.756 * *$ & $.797 * *$ & $.810^{* *}$ & $.339 * *$ & 1 & & & \\
\hline 6. Size & 1.4131 & 0.25423 & 0.007 & -0.065 & 0.131 & 0.026 & 0.28 & 1 & & \\
\hline 7. Age & 11.9219 & $1.32 \mathrm{E}+01$ & 0.226 & 0.21 & 0.156 & 0.08 & 0.218 & 0.145 & 1 & \\
\hline 8. Profit & 16.2721 & 5.08048 & $.378 * *$ & 0.183 & 0.124 & $.305^{*}$ & $.273 *$ & 0.004 & 0.206 & 1 \\
\hline \multicolumn{11}{|l|}{ Micro Scale } \\
\hline Variables & Mean & S.D. & 1 & 2 & 3 & 4 & 5 & 6 & 7 & 8 \\
\hline 1. Goals & 4.0341 & 0.89954 & 1 & & & & & & & \\
\hline 2. Analysis & 3.1567 & 1.2723 & $.427 * *$ & 1 & & & & & & \\
\hline 3. Scanning & 3.3697 & 1.12403 & $.503 * *$ & $.615^{* * *}$ & 1 & & & & & \\
\hline 4. Control & 3.6869 & 0.68496 & $.327 * *$ & $.326^{* *}$ & $.395 * *$ & 1 & & & & \\
\hline 5. Overall Planning & 3.483 & 0.90738 & $.735 * *$ & $.860^{* *}$ & $.865^{* *}$ & 0.121 & 1 & & & \\
\hline 6. Size & 0.6686 & 0.26196 & -0.117 & 0.135 & 0.076 & $-.217 *$ & 0.051 & 1 & & \\
\hline 7. Age & 7.1818 & $1.28 \mathrm{E}+01$ & -0.027 & 0.104 & -0.052 & -0.099 & 0.018 & -0.089 & 1 & \\
\hline 8. Profit & 13.9221 & 5.39655 & 0.267 & 0.127 & $0.389 *$ & 0.116 & $.420 * *$ & -0.103 & 0.041 & 1 \\
\hline
\end{tabular}

Table 2: Correlations with Profitability - Controlling for Age, Firm Size and CEO Locus

\begin{tabular}{|c|c|c|c|}
\hline & Micro Scale & Small Scale & Difference \\
\hline Goal Setting & .242 & $.268 *$ & $*$ \\
\hline Analysis & .101 & .121 & Ns \\
\hline Scanning & $.335 * *$ & .134 & $* * * *$ \\
\hline \multirow[t]{2}{*}{ Overall Planning } & $.318 * *$ & $.259 *$ & $* *$ \\
\hline & Micro Scale & Large Scale & \\
\hline Goal Setting & .242 & .112 & Ns \\
\hline Analysis & .101 & .086 & Ns \\
\hline Scanning & $.335 * *$ & .246 & $*$ \\
\hline \multirow[t]{2}{*}{ Overall Planning } & $.318^{* * *}$ & .105 & $* * *$ \\
\hline & Small Scale & Large Scale & \\
\hline Goal Setting & $.268^{*}$ & .112 & $*$ \\
\hline Analysis & .121 & .086 & Ns \\
\hline Scanning & .134 & .246 & Ns \\
\hline Overall Planning & $.259 *$ & .105 & $* *$ \\
\hline
\end{tabular}

*** Correlation is significant at the 0.01 level (2-tailed).

**Correlation is significant at the 0.05 level (2-tailed).

*Correlation is significant at the 0.10 level (2-tailed)

(C) 2012 The Clute Institute http://www.cluteinstitute.com/ 
As Table 2 shows, the partial planning-performance correlation for large firms ranges from $r=0.86$ to $r$ $=.246$; overall planning has a correlation coefficient of $r=.105$. In the informal sector, where a relative planning disequilibrium exists, the planning and profitability correlation coefficients for micro and small firms are not only greater but reveal a significant correlation between overall planning and performance. For micro firms (ranging between $r=.101$ and $r=.335$ ), two out of the four planning variables are statistically significant, while only one variable is statistically significant for small firms (ranging between $r=.121$ and $r=.268$ ).

Indeed, when all firm groups are considered together for a composite analysis ascertaining the behavior of the variables of interest, we still find that overall planning correlates positively and significantly with performance, with the correlation ranging between $r=0.76$ and $r=.130$. Two of the four planning variables were significantly related to performance.

Table 3: Partial Correlation of Strategic Planning and Profitability Using Total Group of Firms

\begin{tabular}{|l|c|}
\hline & Correlation \\
\hline Goal Setting & $.130^{*}$ \\
\hline Analysis & .076 \\
\hline Scanning & .090 \\
\hline Overall Planning & $.124^{*}$ \\
\hline
\end{tabular}

* Correlation is significant at the 0.10 level (2-tailed).

Note: Tests were conducted using age of firms, firm size, and CEO locus of control, as control variables.

To gauge the planning variables' true impact on profits, an OLS technique was conducted to test the significance of the variables and verify whether the results of the partial correlation were consistent. The regression analysis confirmed that planning in large firms is more widely disseminated than in small and micro firms and that the impact of planning on overall business performance is more significant for small and micro firms than for large firms. The evidence also proved that the impact of strategic planning on profits is greater for micro firms than for small firms, which is consistent with hypothesis 3 . The composite analysis once again demonstrated that overall planning is significantly and directly associated with performance. It can therefore be deduced that Ghanaian businesses generally do not engage in the vigorous planning conducted by their counterparts in developed countries. This was expected because developed economies offer many business schools, training institutions, resource centers, and prudent management information systems readily available for the perusal, adaptation, and coaching of the business community. The results of the regression analysis are presented in Table 4 below:

Table 4: Regression Analysis

\begin{tabular}{|l|c|c|c|c|}
\hline \multicolumn{1}{|c|}{ Variables } & EQN-Micro & EQN2- Small & EQN3-Large & EQN- Overall \\
\hline Goals & .426 & 1.408 & .879 & $.520^{*}$ \\
\hline Analysis & 933 & .718 & .589 & .023 \\
\hline Scanning & $1.598^{*}$ & .054 & 1.434 & .043 \\
\hline Ceo Control & .644 & 1.184 & .364 & $.460^{*}$ \\
\hline Overall Planning & $1.355^{* *}$ & $1.256^{*}$ & .053 & $.938^{* *}$ \\
\hline Firm Size & .018 & .093 & .811 & $.840^{* * *}$ \\
\hline Constant & $12.305^{* * *}$ & $7.854^{* *}$ & $10.943^{* *}$ & $3.458^{* * *}$ \\
\hline & & & & 0.161 \\
\hline Adjusted R-Squared & 0.324 & 0.233 & & \\
\hline
\end{tabular}

$* * *$ Correlation is significant at the 0.01 level (2-tailed).

**Correlation is significant at the 0.05 level (2-tailed).

*Correlation is significant at the 0.10 level (2-tailed).

\section{DISCUSSION}

Our research survey confirms that strategic planning has a positive relationship with performance and that its strength depends on whether the industry or business setting is conversant with planning strategy models, tools, and practices. This study thus confirms the strategic management research works that have observed this linkage. We can therefore postulate that Ghana's business community is not abreast of strategic planning practices. Although large firms in Ghana undertake extensive planning activities, no such planning activities occur in the informal 
sector. The relationship between strategic planning and business performance is not as significant for large firms as for micro and small firms; however, large firms should not abandon or reduce their current planning levels. Our results merely reflect a planning equilibrium. Indeed, if a significant number of competitive firms abandon strategic planning, a positive and significant planning-performance relationship will likely emerge, returning firms to their current equilibrium (Powell, 1992).

\section{AUTHOR INFORMATION}

Ahmed Agyapong is a Lecturer at the Department of Marketing and Corporate Strategy, Kwame Nkrumah University of Science and Technology, Ghana. He holds qualifications in MBA, MA, BA, Dip in Marketing and is currently pursuing a PHD in Corporate Strategies. His research interests are corporate strategies, family business strategies and strategies for SMEs. Ahmed has taught Marketing management and Strategic Management and Policy at both Undergraduate and Masters Levels for over five years. E-mail: deedat31@yahoo.co.uk (Corresponding author)

Abdul Samed Muntaka is a Lecturer at the Department of Information Systems and Decision Sciences, Kwame Nkrumah University of Science and Technology, Ghana. He holds BA in Economics and Geography from the Kwame Nkrumah University of Science and Technology, an MSC degree in Urban Affairs from Hunter College, and an MPA in Public Administration from John Jay College of Criminal Justice all of the City University of New York. Muntaka has taught courses in Business Economics, Supply Chain Management, and Transportation Management at the undergraduate level and Project Management at both the undergraduate and graduate levels for over four years. E-mail: abusamgh@yahoo.com

\section{REFERENCES}

1. Acquaah M. (2011), 'The Impact of Managerial Networking Relationships on Organization Performance in Sub-Saharan Africa. Evidence from Ghana' Organization Management Journal, 3, pp - 115-138

2. Amstrong J. S. (1986). 'The value of formal planning for strategic decisions: Reply', strategic management journal, 7, pp. 183-185.

3. Amstrong, J. S. (1982), 'The value of formal planning for strategic decisions: Review of empirical research' strategic management journal, 3, pp. 197-211

4. Armstrong, J. S. (1991), 'Strategic Planning Improves Manufacturing Performance,' Long Range Planning 24(4), 127-129.

5. Boone, C., Bert De Brabander, ArjenVan Witteloostuijn (1996), 'CEO Locus of Control and Small Firm Performance: An Integrative Framework And Empirical Test', Journal Of Management Studies 33:5 (00222380)

6. Edgley, G. J. (1990). 'Strategic Planning' Association Management, March, pp. 77-80

7. Gunasekaran et. Al. (2004) 'Measuring Supply Chain Performance: Current research and Future Directions.' International Journal of Productivity and Performance Management, 55, Issue 3/4, pp. 242-258

8. Herberg F. (1984), 'Mystery Systems Shape Loyalties', Industry Week, 12 November: 101-104

9. Matthew R. Fairholm (2009) ‘Leadership and Organizational Strategy’ Public Sector Innovation Journal, 14 , article 3

10. Mathew R. F. and Michael C. (2009). 'Perspectives of Strategic Thinking: From Controlling Chaos to Embracing it' Journal of Management and Organization, 15, issue 1, pp. 17-31.

11. Minzberg H. (1994), 'The Fall and Rise of Strategic Planning' Harvard Business Review, 1, pp. 107-144

12. Moore M. H. (1995), 'Creating Public Value: Strategic Management in Government'. Harvard University Press, Cambridge Massachusetts.

13. Pearce, J., II, E, Freeman and R. Robinson, (1987), 'The tenuous link between formal strategic planning and financial performance' Academy of Management Review, 12, pp 658-675

14. Perry, S. (2001), 'The Relationship between Written Business Plans and the Failure of Small Businesses in the US,' Journal of Small Business Management 39(3), 201-208.

15. Powell, T. C. (1992), 'Strategic Planning as Competitive Advantage' Strategic Management Journal, 15, pp. 551-558 
16. Rue, L., and N. Ibrahim, (1998) 'The Relationship between Planning Sophistication and Performance in Small Businesses,' Journal of Small Business Management 36(4), 24-32.

17. Sanders T. I. (1998), 'Strategic Thinking and the New Science: Planning in the Midst of Chaos Complexity and Change'. Free Press, New York

18. Shrader et. al. (1984), 'Strategic and operational planning, uncertainty, and performance in small firms', Journal of Small Business Management, 27, pp. 45-50.

19. Wilson I. (1994), 'Strategic Planning isn't dead - it changed', Long Range Planning 27, 4: pp. 12-16 